\title{
Low-Velocity Impact Response and Experimental Optimization of Modified Fiber Metal Laminates with Integrated Mechanical Interlock Bonding System
}

\author{
Tran-Vu Nong, M.S.A ElSayed* \\ Dept. of Mechanical and Aerospace Engineering \\ Carleton University \\ Ottawa, Canada \\ *Mostafa.elsayed@carleton.ca
}

\author{
Thomas Letellier \\ École Nationale Supérieure de Mécanique et \\ d'Aérotechnique (ISAE-ENSMA) \\ Poitou-Charentes, France \\ thomas.letellier@etu.isae-ensma.fr
}

\begin{abstract}
This paper presents a modified version of fiber metal laminates with integrated mechanical interlock bonding system for aerospace applications. Sheet metals of Al 2024-T3 with surface machined infinitesimal hooks are used along with impregnated glass fiber composites to manufacture a modified version of GLAss REinforced aluminum (GLARE). Low-velocity impact responses of the modified GLARE is examined using a drop weight impact testing machine at an impact energy of 7.5 J. To optimize the geometry of the machined hooks to maximize the modified GLARE low-velocity impact resistance, we developed and tested four configurations of modified GLARE with four variants of hooks' geometry, including two hook sizes, namely, nano and micro and two hook profiles, namely, curved and straight. Impact tests show that modified GLARE with Straight Nano Hooks (SNH) have comparable dynamic responses to the standard GLARE (without hooks), while experiencing much less delamination and fiber damage. Microscopic inspection of the four configurations of modified GLARE also illustrates that SNHs generate modified GLARE with minimal manufacturing defects. The results obtained indicate that $\mathrm{SNH}$ is the optimum hook geometry for the development of modified GLARE. It can be considered as an alternative surface treatment for sheet metals in FML development process as it offers a modified version of the material with comparable impact responses to those manufactured by the industrial standard methodology but at a fraction of production cost.
\end{abstract}

Keywords: Fiber Metal Laminates, Experimental Optimization, Surface Topology, Structured Materials, Aerospace Materials, GLARE

\section{INTRODUCTION}

Increasing demands in aerospace industries for highperformance and lightweight structures with cost-effective manufacturability have stimulated a strong trend towards the development of refined models of hybrid materials such as Fiber-metal laminates (FMLs). While FMLs possess better specific mechanical properties compared to traditional aerospace materials, it is also several times more expensive.
This can be attributed to the costly surface treatments and manufacturing processes designed to improve the adhesion bonding between FML layers to minimize its consistency failures. Particularly, surface topology optimization is a key element to maximize adhesion bonding between FML layers.

Developed during the late 1980s at Delft University, GLARE was the second generation of FMLs. Through its high-strength glass Fiber Reinforced Polymers (FRP) layers, GLARE possesses better impact behavior compared to monolithic aluminum alloys and FRPs $[1,2,3]$. GLARE also possesses superior tensile strength compared to monolithic aluminum alloys [3]. In addition, GLARE is extremely resistant to environmental factors such as moisture, fire, corrosion, and lightning, and can be machined and repaired using common techniques used for aluminum alloys $[4,5,6]$. With its low density compared to monolithic aluminum alloys, GLARE can offer weight savings of up to $25 \%[1,7,8]$. Given these promising properties, GLARE has been used in a variety of applications in the aerospace industry, such as in the cargo floor of the Boeing B777, the upper fuselage of the Airbus A 380, and as bonded repair patches $[3,4,8,9]$.

Given that low-velocity impacts are common in aerospace structures during operation, improving the low-velocity impact response of GLARE is very important [10]. This can be done by preventing the common modes of failure that occur during impact. From existing literature [11, 12], delamination and debonding tend to be among the most important failure modes for laminated structures such as GLARE [11]. Studies have been done to prevent this type of failure by improving the adhesion at the internal interfaces between layers through metal surface treatments. Botelho et al. [12] investigated the effects of sulphuric chromic acid etching and chromic acid anodizing on the interfacial adhesion of GLARE and found that both surface treatments improved the adhesion between the aluminum and the FRP layers compared to non-treated aluminum. Ostapiuk et al. [13] found similar results with regards to sulphuric acid anodizing as well. However, these surface treatments are 
expensive and/or require specialized equipment. Since one of the main disadvantages of

GLARE is its high unit cost compared to aluminum, a more cost-effective solution should be found $[7,8,9]$.

In this study, the low-velocity impact behavior of a novel GLARE variant using a low-cost technology, developed by our industrial partner, is investigated. Here, machined hooks are created on the surface of sheet metal aluminum. During the curing cycle of the GLARE, those hooks penetrate the FRP layers creating an integrated mechanical interlock bonding system. While the modified GLARE possesses mechanical properties similar or comparable to those of GLARE build using the standard methodology available in the aerospace industry, the hook formation process is less costly compared to other surface treatment methods used to improve consistency failure. Moreover, we used the hotpress method to build our samples which is very cheap compared to the infrastructure required for the autoclave manufacturing process which further reduces the cost.

This paper is organized in five sections. After this introduction, the manufacturing process of the modified GLARE is explained in section 2. The test setup, procedures and results for impact testing are presented in section 3 . Mechanical characterization results obtained through tensile testing are presented in section 4. The paper is concluded in section 5 .

\section{MODIFIED GLARE}

\section{A. Lay-up}

We based the lay-up of the modified GLARE on those of GLARE-3 [14]. The lay-up of the modified GLARE is formed of three layers of aluminum 2024-T3 (two external layers with single-sided hooks and one middle layer with double-sided hooks) alternating with two pre-impregnated (pregregs) glass fiber layers. We used fiber layers consisting of $0.008 "(0.20 \mathrm{~mm})$ thick of $8 \mathrm{H}$ satin glass fiber weaved prepregs supplied by ACP Composites [15]. This is chosen due to availability, cost, and storage requirements.

To optimize the geometry of the hooks, four configurations of modified GLARE are considered in this study. The different configurations are based on geometry variants of the machined hooks including two hook sizes as well as two hook profiles. Table 1 summarizes the lay-up specifications of the four configurations of modified GLARE considered as well as those of the standard GLARE (with no-hooks).

\section{B. Hooks Development}

0.016" (0.40 mm) thick ALCLAD 2024-T3 aluminum sheet metals are used. Nano and micro hooks with straight and curved profiles are machined on the surface of sheet metals using the manufacturing services at our industrial partner. Due to tooling limitations, we are able to machine the hooks on only a 6" wide sheet metal strips. The sheet metal strips are cut into 12 " in length to fit within the hot-press available for the manufacturing of GLARE. Fig. 1 shows microscopic images of the machined sheet metal with straight and curved hooks.

TABLE I. LAY-UP SUMMARY OF THE STANDARD AND MODIFIED GLARE

\begin{tabular}{|c|c|c|c|c|c|}
\hline & \multirow[b]{2}{*}{$\begin{array}{l}\text { Standard } \\
\text { (No-Hooks) }\end{array}$} & \multicolumn{4}{|c|}{ Modified GLARE } \\
\hline & & $\begin{array}{c}\text { Straight } \\
\text { Nano } \\
\text { Hooks } \\
\text { (SNH) } \\
\end{array}$ & $\begin{array}{c}\text { Straight } \\
\text { Micro } \\
\text { Hooks } \\
\text { (SMH) }\end{array}$ & $\begin{array}{c}\text { Curved } \\
\text { Nano } \\
\text { Hooks } \\
\text { (CNH) } \\
\end{array}$ & $\begin{array}{l}\text { Curved } \\
\text { Micro } \\
\text { Hooks } \\
(\text { CMH) } \\
\end{array}$ \\
\hline & 2024-T3 & 2024-T3 & 2024-T3 & 2024-T3 & 2024-T3 \\
\hline Metal Layer & $\begin{array}{l}\text { ALCLAD } \\
\text { aluminum }\end{array}$ & $\begin{array}{l}\text { ALCLAD } \\
\text { aluminum }\end{array}$ & $\begin{array}{l}\text { ALCLAD } \\
\text { aluminum }\end{array}$ & $\begin{array}{l}\text { ALCLAD } \\
\text { aluminum }\end{array}$ & $\begin{array}{l}\text { ALCLAD } \\
\text { aluminum }\end{array}$ \\
\hline $\begin{array}{c}\text { Metal } \\
\text { Thickness }\end{array}$ & $\begin{array}{c}0.016 "(0.40 \\
\mathrm{mm})\end{array}$ & $\begin{array}{c}0.016 " \\
(0.40 \mathrm{~mm})\end{array}$ & $\begin{array}{c}0.016 " \\
(0.40 \mathrm{~mm})\end{array}$ & $\begin{array}{c}0.016 " \\
(0.40 \mathrm{~mm})\end{array}$ & $\begin{array}{c}0.016 " \\
(0.40 \mathrm{~mm})\end{array}$ \\
\hline $\begin{array}{l}\text { No. of No- } \\
\text { Hooks } \\
\text { Layer }\end{array}$ & 3 sheets & - & - & - & - \\
\hline $\begin{array}{c}\text { No. of } \\
\text { Hooked } \\
\text { Layer }\end{array}$ & - & $\begin{array}{l}2 \text { single- } \\
\text { sided, } \\
1 \text { double- } \\
\text { sided }\end{array}$ & $\begin{array}{l}2 \text { single- } \\
\text { sided, } \\
1 \text { double- } \\
\text { sided }\end{array}$ & $\begin{array}{l}2 \text { single- } \\
\text { sided, } \\
1 \text { double- } \\
\text { sided }\end{array}$ & $\begin{array}{l}2 \text { single- } \\
\text { sided, } \\
1 \text { double- } \\
\text { sided }\end{array}$ \\
\hline Hook Type & 一 & $\begin{array}{l}\text { Straight- } \\
\text { profile } \\
\text { nano } \\
\text { hooks }\end{array}$ & $\begin{array}{l}\text { Straight- } \\
\text { profile } \\
\text { micro } \\
\text { hooks }\end{array}$ & $\begin{array}{l}\text { Curved- } \\
\text { profile } \\
\text { nano } \\
\text { hooks }\end{array}$ & $\begin{array}{l}\text { Curved- } \\
\text { profile } \\
\text { micro } \\
\text { hooks }\end{array}$ \\
\hline $\begin{array}{l}\text { Hook } \\
\text { Height }\end{array}$ & - & $\begin{array}{c}0.008 " \\
(0.20 \mathrm{~mm})\end{array}$ & $\begin{array}{c}0.028 " \\
(0.70 \mathrm{~mm})\end{array}$ & $\begin{array}{c}0.008 " \\
(0.20 \mathrm{~mm})\end{array}$ & $\begin{array}{c}0.028 " \\
(0.70 \mathrm{~mm})\end{array}$ \\
\hline Hook Width & 一 & $\begin{array}{c}0.0012 ” \\
(0.03 \mathrm{~mm})\end{array}$ & $\begin{array}{c}0.0042 ” \\
(0.11 \mathrm{~mm})\end{array}$ & $\begin{array}{c}0.0012 ” \\
(0.03 \mathrm{~mm})\end{array}$ & $\begin{array}{c}0.0042 " \\
(0.11 \mathrm{~mm})\end{array}$ \\
\hline $\begin{array}{c}\text { Hook } \\
\text { Density }\end{array}$ & 一 & $\begin{array}{c}250-260 \\
\text { hooks/in }{ }^{2} \\
\text { (single- } \\
\text { sided), } \\
240-250 \\
\text { hooks/in }{ }^{2} \\
\text { per side } \\
\text { (double- } \\
\text { sided) }\end{array}$ & $\begin{array}{c}250-260 \\
\text { hooks/in } \\
\text { (single- } \\
\text { sided), } \\
240-250 \\
\text { hooks/in } \\
\text { per side } \\
\text { (double- } \\
\text { sided) }\end{array}$ & $\begin{array}{c}250-260 \\
\text { hooks/in² } \\
\text { (single- } \\
\text { sided), } \\
240-250 \\
\text { hooks/in }{ }^{2} \\
\text { per side } \\
\text { (double- } \\
\text { sided) }\end{array}$ & $\begin{array}{c}250-260 \\
\text { hooks } / \text { in }^{2} \\
\text { (single- } \\
\text { sided), } \\
240-250 \\
\text { hooks/in } \\
\text { per side } \\
\text { (double- } \\
\text { sided) }\end{array}$ \\
\hline $\begin{array}{c}\text { Prepreg } \\
\text { Layer } \\
\text { (ACP } \\
\text { Composite) }\end{array}$ & $\begin{array}{l}\text { E-glass fabric } \\
\text { impregnated } \\
\text { with a } \\
\text { thermosetting } \\
\text { epoxy resin } \\
\text { system }\end{array}$ & $\begin{array}{c}\text { E-glass } \\
\text { fabric } \\
\text { impregnate } \\
\text { d with a } \\
\text { thermosetti } \\
\text { ng epoxy } \\
\text { resin } \\
\text { system }\end{array}$ & $\begin{array}{c}\text { E-glass } \\
\text { fabric } \\
\text { impregnate } \\
\text { d with a } \\
\text { thermosetti } \\
\text { ng epoxy } \\
\text { resin } \\
\text { system }\end{array}$ & $\begin{array}{l}\text { E-glass } \\
\text { fabric } \\
\text { impregnate } \\
\text { d with a } \\
\text { thermosetti } \\
\text { ng epoxy } \\
\text { resin } \\
\text { system }\end{array}$ & $\begin{array}{c}\text { E-glass } \\
\text { fabric } \\
\text { impregnate } \\
\text { d with a } \\
\text { thermosetti } \\
\text { ng epoxy } \\
\text { resin } \\
\text { system }\end{array}$ \\
\hline $\begin{array}{c}\text { Prepreg } \\
\text { Thickness }\end{array}$ & $\begin{array}{c}0.008 "(0.20 \\
\mathrm{mm})\end{array}$ & $\begin{array}{c}0.008 " \\
(0.20 \mathrm{~mm})\end{array}$ & $\begin{array}{c}0.008 " \\
(0.20 \mathrm{~mm})\end{array}$ & $\begin{array}{c}0.008 " \\
(0.20 \mathrm{~mm})\end{array}$ & $\begin{array}{c}0.008^{\prime \prime} \\
(0.20 \mathrm{~mm})\end{array}$ \\
\hline $\begin{array}{l}\text { Prepreg } \\
\text { Type }\end{array}$ & $\begin{array}{c}57 \times 548 \mathrm{H} \\
\text { Satin Weave }\end{array}$ & $\begin{array}{c}57 \times 548 \mathrm{H} \\
\text { Satin } \\
\text { Weave } \\
\end{array}$ & $\begin{array}{c}57 \times 548 \mathrm{H} \\
\text { Satin } \\
\text { Weave } \\
\end{array}$ & $\begin{array}{c}57 \times 548 \mathrm{H} \\
\text { Satin } \\
\text { Weave } \\
\end{array}$ & $\begin{array}{c}57 \times 548 \mathrm{H} \\
\text { Satin } \\
\text { Weave }\end{array}$ \\
\hline $\begin{array}{c}\text { Resin } \\
\text { Content }\end{array}$ & $30 \%+/-3 \%$ & $\begin{array}{c}30 \%+/- \\
3 \% \\
\end{array}$ & $\begin{array}{c}30 \%+/- \\
3 \% \\
\end{array}$ & $\begin{array}{c}30 \%+/- \\
3 \% \\
\end{array}$ & $\begin{array}{c}30 \%+/- \\
3 \% \\
\end{array}$ \\
\hline $\begin{array}{c}\text { Surface } \\
\text { Treatments }\end{array}$ & $\begin{array}{c}\text { Grit blasting, } \\
\text { AC-130-2 } \\
\text { sol-gel by } \\
\text { 3M }\end{array}$ & - & 一 & - & - \\
\hline
\end{tabular}

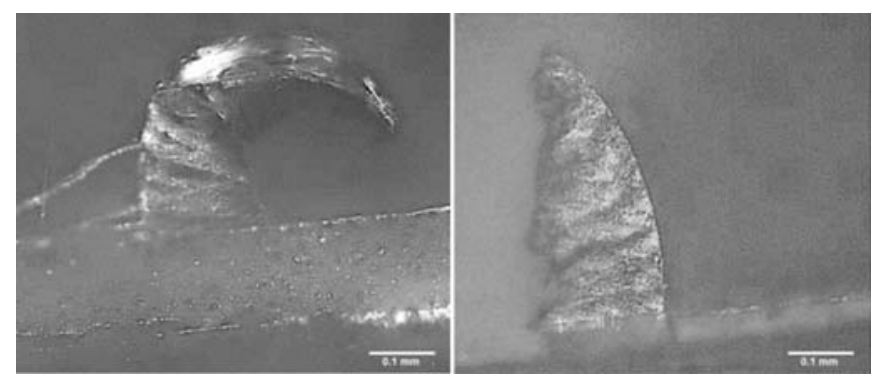

Figure 1. Microscopic view of CMH (left) and SMH (right) using AmScope Inverted Trinocular Metallurgical Microscope 


\section{Manufacturing}

The GLARE manufacturing process can be summarized into four distinct stages, namely, cleaning, lay-up, curing, and cutting. Prior to lay-up and curing, the prepreg layers are cut to $152 \times 304 \mathrm{~mm}^{2}\left(6 \times 12 \mathrm{in}^{2}\right)$ and debulked in a cold hydraulic press at 1.4 metric tons of pressure for 12 hours to remove any air pockets before lay-up.

The sheet metals are then degreased with methyl ethyl ketone (MEK) followed by cleaning in an ultrasonic bath using $100 \mathrm{~mL}$ of soap and $20 \mathrm{~L}$ of water for 15 minutes, before being thoroughly rinsed with tap water and wiped down with isopropyl alcohol, as shown in Fig. 4.

Following industry standards for the manufacturing of standard GLARE, prior to lay-up, no-hook sheet metal layers, used to manufacture the standard GLARE, are further treated with grit blasting using silica sand at 110 psi and then sprayed with $40 \mathrm{~mL}$ of AC-130-2 Sol-Gel, produced by $3 \mathrm{M}$ [16]. The Sol-Gel is then left to dry for 1 hour before beginning the lay-up of the standard GLARE. Sol-Gel forms an organic layer which promotes bonding between layers.

Prior to curing, the laid-up panels are debulked once again in a hydraulic press at 1.4 metric tons of pressure for 1 hour at room temperature to promote adhesion and to remove any air trapped during lay-up. Curing was done in house using a heated Carver pneumatic press at a pressure of 1.6 tons, as shown in Fig. 4. The temperature was increased from room temperature to $310^{\circ} \mathrm{F}$ at an approximate rate of $5^{\circ} \mathrm{F} / \mathrm{min}$, then cured for an hour at $310^{\circ} \mathrm{F}$ before being left to cool to room temperature. Cured samples are then removed from the press once their temperature fell below $140{ }^{\circ} \mathrm{F}$ (after approximately four hours).

Test samples are cut from the manufactured GLARE panels using a UHAP Smart Cut 6100 composite wet saw to the dimensions described in Section 3.2. The saw uses a nickel bond diamond wafering blade lubricated with distilled water to accurately cut samples to size with a precision of 0.13 $\mathrm{mm}(0.05 \mathrm{in})$.

\section{Microscopic Investigation}

To check the quality of the modified GLARE panels, pretesting microscopic analysis is conducted. Cross-sections are cut from a random selection of the manufactured panels and inspected using an optical microscope, as shown in Figs 2-5.

As shown in Fig. 2, GLARE with SNH showed the best manufacturing quality. It is observed that SNHs are able to penetrate well into the fiberglass composite which resulted in a very good integration at the interface of the different layers of the material. However, in few locations the hooks are found not penetrating the fibers and instead, the fibers are bending around the hooks creating potential gaps and fiber breakage, as shown in Fig. 2. A potential solution to this includes using a fiberglass weave with lower fiber density as well as redesigning the hooks with straight, sharper, pin profile.

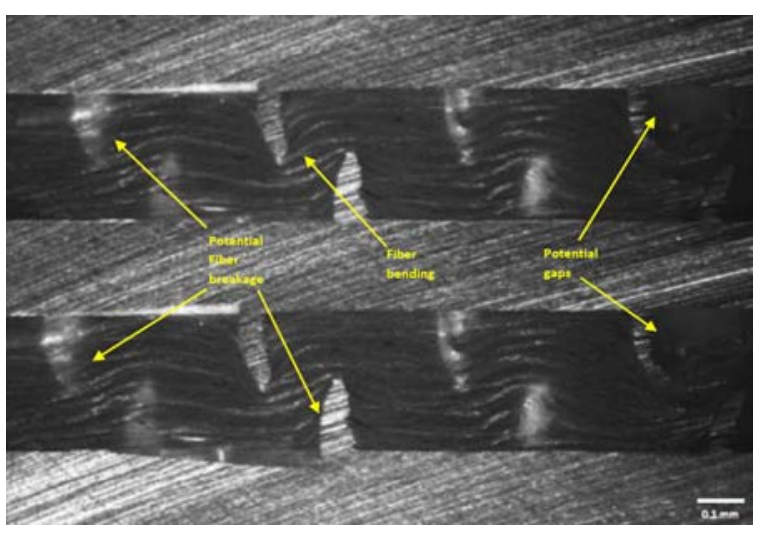

Figure 2. Microscopic view of modified GLARE with SNH using AmScope Inverted Trinocular Metallurgical Microscope

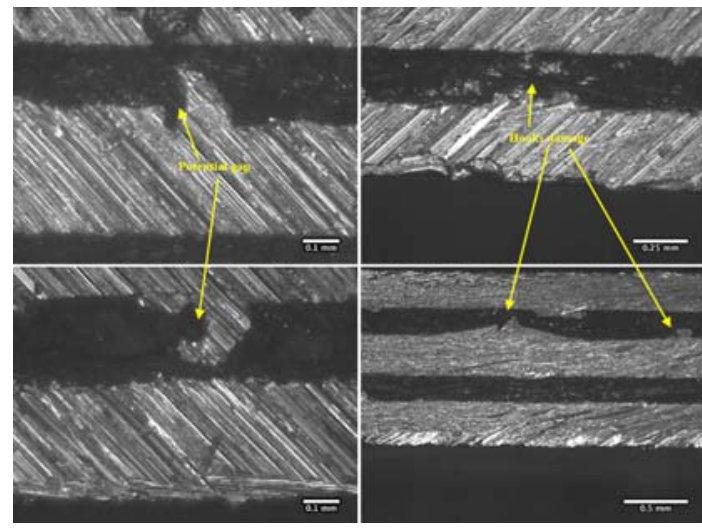

Figure 3. Four microscopic views of modified GLARE with CNH using AmScope Inverted Trinocular Metallurgical Microscope

As shown in Fig. 3, microscopic inspection of modified GLARE with CNH showed several manufacturing flaws including hooks crushing and breakage as well as development of gaps and fiber breakage. This can be attributed to the curved hook profile which significantly reduce the penetration capability of the hooks into the composite layers.

Modified GLARE with micro hooks showed the worst manufacturing quality. As shown in Fig. 4 and 5, most of the $\mathrm{SMH}$ and $\mathrm{CMH}$ are either crushed under pressure during curing or resulted in fiber breakage and development of several gaps.

\section{LOW-VELOCITY IMPACT TESTING}

\section{A. Test Setup}

Low velocity impact tests were performed using an Instron Dynatup 8200 drop weight impact tower following ASTM D7136/D7136-M [17]. A hemispherical impactor with a diameter of $25.4 \mathrm{~mm}$ and a mass of $10.1 \mathrm{~kg}$ was used in all tests. Samples were clamped using a custom-built impact fixture modelled after the impact fixture used by Laliberte et al. [18], shown in Fig. 6. The impact fixture had a filleted circular opening with a diameter of $112 \mathrm{~mm}(4.4 \mathrm{in})$ to 
prevent corner and edge deformations. Three samples of each GLARE configuration are tested at 7.5J energy level, including one configuration of standard GLARE with nohooks and four configurations of modified GLARE. Samples were cross-sectioned and examined under an optical microscope post-impact to determine internal damages.

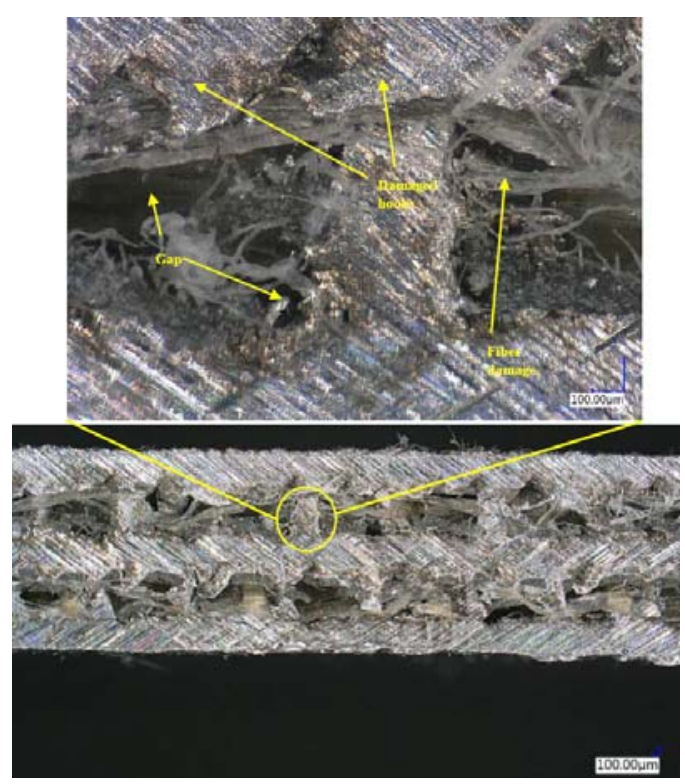

Figure 4. Microscopic views of modified GLARE with SMH using Keyence Digital Microscope VHX-6000 Series

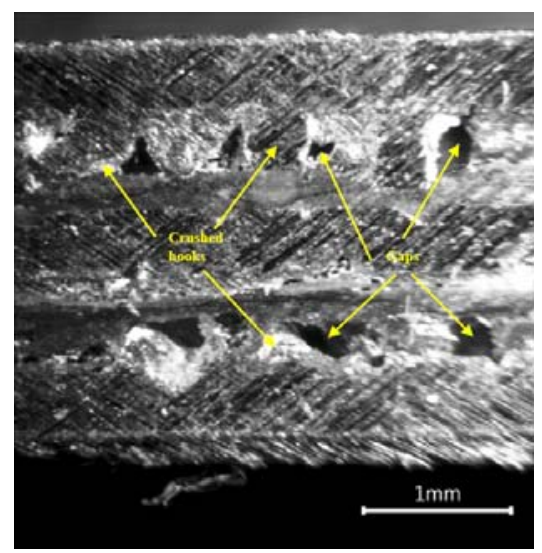

Figure 5. Microscopic view of modified GLARE with CMH using AmScope Inverted Trinocular Metallurgical Microscope

\section{B. Impact Response}

The averaged load versus time curves for each test configuration are shown in Fig. 7. The averaged maximum load of each test configuration is shown in Table 2. As shown in Fig. 7, samples of modified GLARE with nano hooks have similar impact responses to those of standard GLARE. While the modified GLARE with SNH supports a lower maximum load than standard GLARE, as shown in
Table 2, a drop of $2 \%$ is deemed insignificant compared to cost savings during metal sheet surface preparation.

Modified GLARE with micro hooks had worse impact responses compared to modified GLARE with nano hooks and standard GLARE. Despite supporting similar maximum loads to the other GLARE configurations, modified GLARE with micro hooks experienced significant internal failure during impact, as shown by the sharp drop in supported load in Fig. 7. This is attributed to the significant presence of voids and internal defects in the micro-hooked samples, as shown in Figs. 4 and 5.

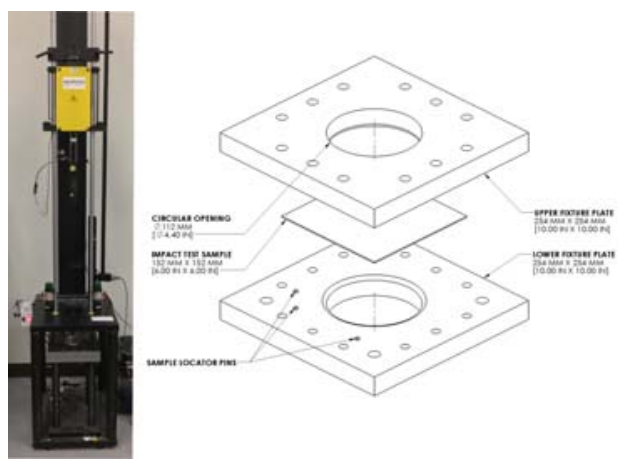

Figure 6. Drop tower (left) and custom impact fixture (right)

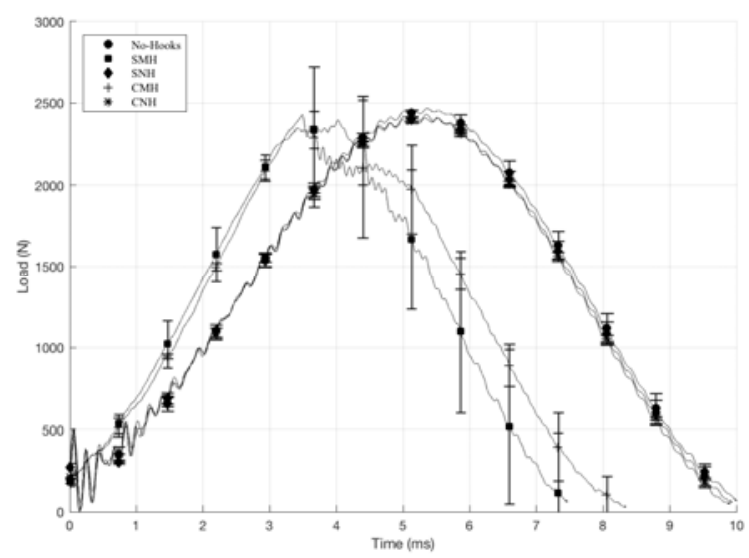

Figure 7. Averaged load v. time curves for each test configuration

TABLE II. AVERAGED MAXIMUM LOAD OF GLARE

\begin{tabular}{|c|c|}
\hline Specimen & $\begin{array}{c}\text { Averaged Maximum Load } \\
(\mathbf{N})\end{array}$ \\
\hline No-hooks & $2571.7 \pm 19.6$ \\
\hline SNH & $2256.5 \pm 0.8$ \\
\hline SMH & $2552.0 \pm 19.6$ \\
\hline CNH & $2529.6 \pm 21.0$ \\
\hline CMH & $2588.3 \pm 156.4$ \\
\hline
\end{tabular}

\section{Damage Assessment}

Fig. 8 shows a representative internal cross-section of each test configuration. As shown in Fig. 8, modified GLARE 
with nano hooks experienced significantly less delamination and fiber breakage than standard GLARE.

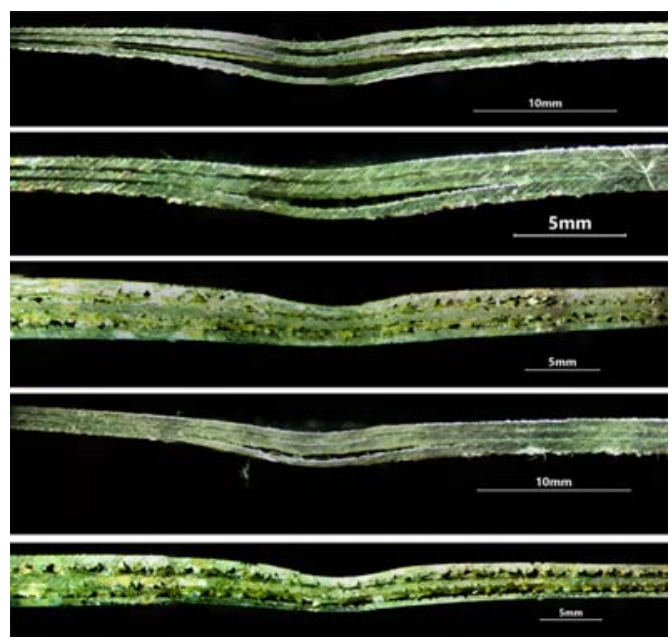

Figure 8. Internal cross sections of samples at $7.5 \mathrm{~J}$, in the following order from top to bottom: standard GLARE, SNH, SMH, CNH, CMH

Standard GLARE samples also possess a larger internal damage area, as internal damages extend far beyond the impactor dent. This can be attributed to the superior interlocking behavior of the nano hooks. The modified GLARE with micro hooks experience significantly more damage than the other test configurations. In addition to experiencing major fiber breakage near the impactor dent, the modified GLARE with micro hooks are the only test configurations that experience observable cracks in the metal surfaces, as shown in Fig. 8. This is due to the reduction in strength in the metal layers due to hooks machining. Since the hooks are made directly from the sheet metal surfaces, larger hooks would remove more material, reducing its strength. Since nano hooks have smaller hooks, it would not experience as significant of an issue.

\section{MECHANICAL CHARACTERIZATION}

Tensile tests were performed to mechanically characterize the modified GLARE. Tensile tests are performed using 810 Materials Testing System (MTS), shown in Fig. 9. Rectangular test samples are manufactured following ASTM D3039/D3039M [19] with dimensions of $216 \times 22 \mathrm{~mm}^{2}(8.5$ $\mathrm{x} 0.85 \mathrm{in}^{2}$ ) and grip lengths of $47 \mathrm{~mm}$ (1.85 in). Five samples of each GLARE configuration are tested including one configuration of standard GLARE with no-hooks and four configurations of modified GLARE. Samples are tested at a constant load rate of $2.0 \mathrm{~mm} / \mathrm{min}$. Test data was recorded at a frequency of $5.0 \mathrm{~Hz}$.

The averaged stress versus strain curves for each test configuration are shown in Fig. 10. The averaged elastic modulus, yield strength, ultimate tensile strength, and elongation to fracture of each test configuration are shown in Table 3.
All tensile samples of modified GLARE with micro hooks as well as those of standard GLARE experienced significant fiber breakage and edge delamination upon tensile failure, as shown in Fig. 11.
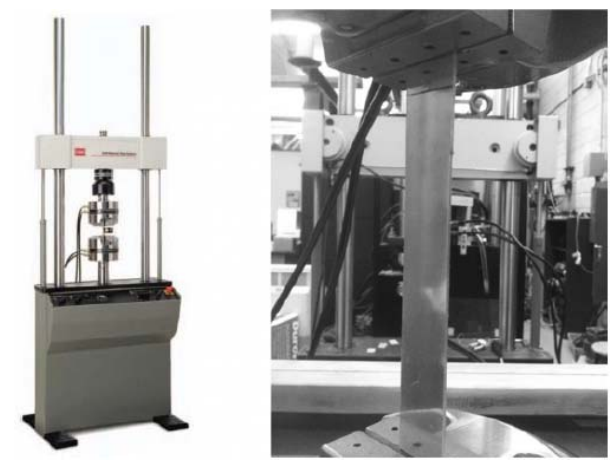

Figure 9. 810 Material Testing System (MTS) (left) and a mounted tensile test sample (right)

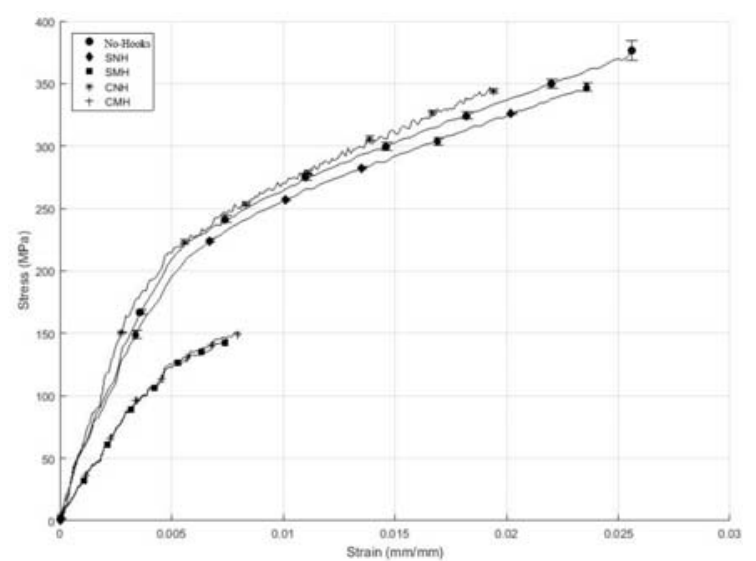

Figure 10. Tensile test results of GLARE

Also, their samples experienced full rupture upon failure, as shown in Fig. 12. Samples of modified GLARE with nano hooks tended to partially fracture, leaving the back metal sheet intact, as shown in Fig. 13. Despite earlier failure of modified GLARE samples with $\mathrm{CNH}$ and at lower ultimate stress level compared to standard GLARE and modified GLARE with SNH, the difference in strength between them lie only within $10 \%-20 \%$. As shown in Fig. 10 and Table 2, modified GLARE with SNH experienced drop of $4.5 \%$ and $3 \%$ in elastic modulus and yield strength, respectively, compared to the standard GLARE.

TABLE III. Tensile Mechanical Properties of GLARE

\begin{tabular}{|c|c|c|c|c|}
\hline Specimen & $\begin{array}{c}\text { Elastic } \\
\text { Modulus } \\
\text { (GPa) }\end{array}$ & $\begin{array}{c}\text { Yield } \\
\text { Strength } \\
\text { (MPa) }\end{array}$ & $\begin{array}{c}\text { Ultimate } \\
\text { Strength } \\
\text { (MPa) }\end{array}$ & $\begin{array}{c}\text { Elongation } \\
\text { to Break } \\
\text { (\%) }\end{array}$ \\
\hline No-hooks & $42.3 \pm 0.3$ & $243.4 \pm 2.3$ & $378.5 \pm 8.8$ & $2.69 \pm 0.1$ \\
\hline SNH & $40.4 \pm 1.6$ & $236.8 \pm 4.6$ & $362.3 \pm 16.8$ & $2.63 \pm 0.29$ \\
\hline SMH & $28.0 \pm 0.02$ & $141.5 \pm 2.3$ & $143.2 \pm 2.6$ & $0.75 \pm 0.02$ \\
\hline CNH & $53.1 \pm 1.4$ & $229.9 \pm 0.8$ & $352.2 \pm 2.8$ & $2.02 \pm 0.07$ \\
\hline CMH & $28.3 \pm 0.5$ & $145.7 \pm 1.8$ & $156.0 \pm 6.0$ & $0.93 \pm 0.15$ \\
\hline
\end{tabular}



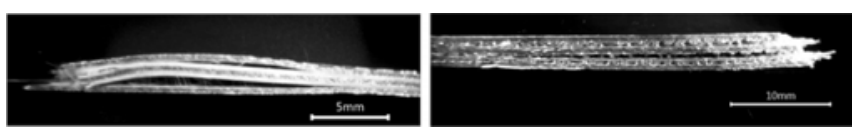

Figure 11. Fiber breakage and delamination in standard GLARE (left) and modified GLARE with CMH (right)
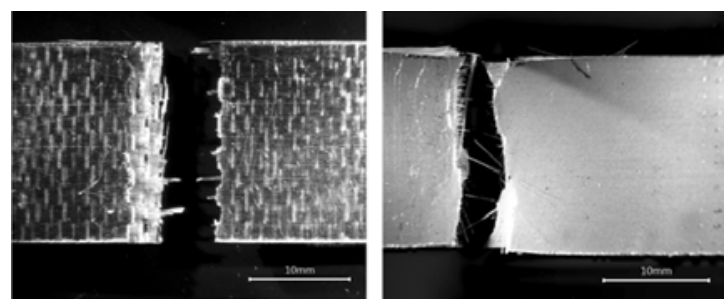

Figure 12. Top view of fractured samples of modified GLARE with $\mathrm{CMH}$ (left) and standard GLARE (right)
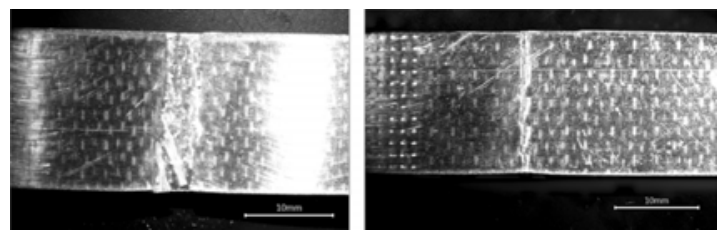

Figure 13. Partial fracture in samples of modified GLARE with SNH (left) and $\mathrm{CNH}$ (right)

The results from the tensile tests agree with the conclusions from the impact tests, namely comparable mechanical responses between the modified GLARE with SNH and standard GLARE, and the superior internal damage resistance of modified GLARE with SNH.

\section{CONCLUSION}

The low-velocity impact response of GLARE samples with and without hooks are experimentally investigated to determine whether machined hooks can be considered as a low-cost alternative to expensive industry-standard methods of improving adhesion in FML manufacturing. Hooks of different sizes and profiles are tested to determine the optimal hook size and profile. The following conclusions are made:

Modified GLARE with SNH samples had comparable dynamic impact responses to standard GLARE samples, while outperforming the standard GLARE samples in terms of the severity and extent of internal damages. While modified GLARE with CNH had comparable behavior to that with $\mathrm{SNH}$, microscopic analysis revealed that $\mathrm{CNHs}$ do not penetrate the fibers in the composite layer due to the shape of its profile.

Micro-hooked samples perform significantly worse compared to all other test configurations in terms of both dynamic response and internal damages. This is due to the high number of voids and internal defects in the microhooked samples, which stem from the composite layer being too thin to fully encompass the larger hooks. In addition, the micro hooks are deformed or damaged due to the clamping pressure exerted on it during manufacturing.

Based on these conclusions, modified GLARE with SNH has the potential to be a viable, low-cost alternative to traditional methods of improving consistency failure in FMLs.

\section{REFERENCES}

[1] A. Vlot, "Impact loading on fibre metal laminates," International Journal of Impact Engineering, vol. 18, no. 3, pp. 291-307, 1996.

[2] J. Bieniaś, B. Surowska and P. Jakubczak, "The Comparison of LowVelocity Impact Resistance of Aluminum/Carbon and Glass Fiber Metal Laminates," Polymer Composites, vol. 37, no. 4, p. 1056-1063, 2016.

[3] G. Wu and J.-M. Yang, "The Mechanical Behavior of GLARE Laminates for Aircraft Structures," JOM, vol. 57, no. 1, pp. 72-79, 2005 .

[4] L. Vogelesang and A. Vlot, "Development of fibre metal laminates for advanced aerospace structures," Journal of Materials Processing Technology, vol. 103, no. 1, pp. 1-5, 2000.

[5] A. Vlot, L. Vogelesang and T. de Vries, "Towards application of fibre metal laminates in large aircraft," Aircraft Engineering and Aerospace Technology, vol. 71, no. 6, pp. 558-570, 1999.

[6] R. Alderliesten and R. Benedictus, "Fiber/Metal Composite Technology for Future Primary Aircraft Structures," Journal of Aircraft, vol. 45, no. 4, pp. 1182-1189, 2008.

[7] A. Asundi and A. Choi, "Fiber Metal Laminates: An Advanced Material for Future Aircraft," Journal of Materials Processing Technology, vol. 63, no. 1-3, pp. 384-394, 1997.

[8] C. Vermeeren, "An Historic Overview of the Development of Fibre Metal Laminates," Applied Composite Materials, vol. 10, no. 4, p. 189-205, 2003.

[9] T. Sinmazçelik, E. Avcu, M. Bora and O. Çoban, "A review: Fibre metal laminates, background, bonding types and applied test methods," Materials and Design, vol. 32, no. 7, p. 3671-3685, 2011.

[10] M. Sadighi, R. Alderliesten and R. Benedictus, "Impact resistance of fiber-metal laminates: A review," International Journal of Impact Engineering, vol. 49, pp. 77-90, 2012.

[11] R. Starikov, "Assessment of impact response of fiber metal laminates," International Journal of Impact Engineering, vol. 59, pp. 38-45, 2013.

[12] E. Botelho, R. Silva, P. L.C. and M. Rezende, "A Review on the Development and Properties of Continuous Fiber/epoxy/aluminum Hybrid Composites for Aircraft Structures," Materials Research, vol. 9, no. 3, pp. 247-256, 2006.

[13] M. Ostapiuk, B. Surowska and J. Bieniaś, "Interface analysis of fiber metal laminates," Composite Interfaces, vol. 21, no. 4, p. 309-318, 2014.

[14] A. Vlot and J. Gunnick, Fiber metal laminates: an introduction, Springer Science \& Business Media, 2001.

[15] "8.8 oz. 8H Satin Weave Fiberglass RTS Prepreg 50"," [Online]. Available: https://store.acpsales.com/products/3261/8-8-oz-8h-satinweave-fiberglass-rts-prepreg-50. [Accessed 4 December 2017].

[16] "3M $\mathrm{M}^{\mathrm{TM}}$ Surface Pre-Treatment AC-130-2," [Online]. Available: https://www.3m.com/3M/en_US/company-us/all-3m-products/ /3MSurface-Pre-Treatment-AC-130-2/?N=5002385+3292667587\&rt=rud. [Accessed 4 December 2017].

[17] Standard Test Method for Measuring the Damage Resistance of a Fiber-Reinforced Polymer Matrix Composite to a Drop-Weight Impact Event, ASTM D7136/D713M-15, 2015.

[18] J. Laliberté, P. Straznicky and C. Poon, "Impact Damage in Fiber Metal Laminates, Part 1: Experiment," AIAA Journal, vol. 43, no. 11, pp. 2445-2453, 2005.

[19] Standard Test Method for Tensile Properties of Polymer Matrix Composite Materials, ASTM D3039/D3039-M-14, 2014. 